\title{
Characteristics of ten-year old self-directed learners
}

\author{
Oxana A. Rydze ${ }^{1, *}$ \\ ${ }^{1}$ ISED RAE, Center for Primary Education, 105062, Moscow, Russia
}

\begin{abstract}
This paper discusses the development of the skill to learn in the context of the Federal State Educational Standard (FSES) requirements of primary education. The author analyses three groups of typical difficulties of the dependent students and gives the examples of their emergence during carrying out mathematics practice test. The article also defines the strategies to develop successful and effective self-directed learners.
\end{abstract}

\section{Introduction}

One of the Federal State Educational Standard requirements is the development of the skill to learn (or 'to teach yourself'). It is at the primary school stage that the student learns to organize his learning activity, to manage, control, adjust and assess his learning skills and operations. The ability to learn and self-management [1] are the self-directed learner's key traits, they are essential in progressing in the general curriculum and mastering activities and methods that might be used in both out-of-school and in-school settings.

The attempt to meet the Federal State Educational Standard requirements revealed a number of achievements and difficulties primary school students face, what eventually made it possible to comment on the modern ten-year old pupil's autonomy. Learner autonomy is a qualitative characteristic of a student as the subject of learning. In $70-90$ s of the $20^{\text {th }}$ century the notion of learner autonomy (or self-directed learning) was further developed by A.Leontiev, D.Elkonin, and V.Davydov. According to the scholars, at the final stage of primary education the self-directed learner can comprehend a task and follow its instructions, he can predict possible difficulties and ways of overcoming them, monitor and assess his own work, as well as demonstrate initiative and creativeness. The self-directed learner goes beyond rule and sample reproduction, stepby-step instructions and directions. He can choose from among methods of solving the problem and consequently assess its efficiency and rationality. The self-directed learner is willing to acquire new knowledge even when he is unaware of its intended purpose and its possible future value. The learner is ready to identify and prioritize the obtained information, as well as to address situations based on analogy. The primary school student's self-assessment and self-control suggest that the pupil can assess his ability to accomplish a task, relate his answer to the correct one, identify, explain, and correct mistakes; moreover, he can describe the course and outcome of his work and comment on his contribution to group decisions. The provided description of the self-directed learner is based on the theoretical analysis of psychological and pedagogical studies by famous scholars (Danilov, M., Osnitskiy, A., Tsukerman, G. and others) and the research in teaching methods conducted in the Primary General Education Centre (under Vinogradova, N.) as the Second Generation Standards and their implementation possibilities in primary education were developed.

\section{How to identify a dependent learner}

First, the other-directed learner finds it difficult to set and stay focused on his learning goals, to complete the task and to check the solution and the answer. Second, the student tries to avoid responsibility for task solving. Furthermore, he starts to perform tasks only after being encouraged by the teacher ("you know how to do this type of exercises", "you'll manage it" and so on) or being given directions, instructions and hints ("try to do it this way..."). It results in the child's substitution of the task suggested in tests with the one he can accomplish according to a familiar algorithm or familiar directions. Third, the dependent learner does not demonstrate a desire to learn, he fails to ask the teacher questions about the material, prefers to complete the minimum number of tasks, and rarely uses available supplemental resources to obtain any additional information, such as commentaries to problem solving and additional texts (for instance, in such sections as "This is interesting!", "Language secrets" and others).

The three groups of challenges induced by dependent learning were subsequently related to fourth graders' results in aptitude tests on the primary school material. All the tasks listed below were taken from the mathematics tests offered to the students by the Center for Educational Quality Assessment of the Institute for Strategy of Education Development of the Russian Academy of Education (ISED RAE) (under Kovaleva, G.S.) and the Moscow Education Quality Center (under

* Corresponding author: oxanarydze@mail.org 
Tatur, A.O.) in 2013-2014 and 2014-2015 school years and were developed by O. Rydze and K. Krasnyanskaya. [2]

The results of the international research TIMSS-2011 (Trends in Mathematics and Science Study) [3] showed that the challenges of self-management and poor learning skills (the inability to monitor the task processing, to test hypotheses, to note all possible solutions to the task, to perform a task from start to finish) could be listed among the main reasons for giving a wrong answer.

Each group of academic dependence cases can be described by providing typical mistakes and possible challenges that were revealed upon offering students problems in mathematics.

\section{What are other-directed students' typical challenges?}

Group one. Primaryschool students find it difficult to process and concentrate on all the conditions of the problem. During tests, nobody tells and hints them what conditions should be selected from the text of the problem and used later to accomplish the task. As a result, the task noted below occurred to be challenging:

Task 1. "Tanya wrote a five-digit odd number, that has the digit 0 in hundred's unit. Choose the number she wrote.
1) 4065
2) 14037
3) 48303
4) $24074 "$

The pupil was to supposed to focus on the three features the number he had to choose possessed and see which number of the fourmet all three requirements. Only $75 \%$ of the fourth graders gave the correct answer (chose answer 2). See Table 1 for an overview of the mistakes made by the others.

Table 1. Mistakes in Task 1

\begin{tabular}{|c|c|c|c|}
\hline $\begin{array}{c}\text { Number } \\
\text { features to } \\
\text { select }\end{array}$ & $\begin{array}{c}\text { Number } \\
\text { features } \\
\text { selected } \\
\text { instead }\end{array}$ & $\begin{array}{c}\text { Students } \\
\text { providing a } \\
\text { wrong answer }\end{array}$ & $\begin{array}{c}\text { Wrong } \\
\text { answer }\end{array}$ \\
\hline Five-digit & Four-digit & $5 \%$ & $1)$ \\
\hline Odd & Even & $16 \%$ & $4)$ \\
\hline $\begin{array}{c}\text { Digit 0 in } \\
\text { hundreds } \\
\text { position }\end{array}$ & $\begin{array}{c}\text { Digit 0 in } \\
\text { tens position }\end{array}$ & $4 \%$ & $3)$ \\
\hline
\end{tabular}

Each of the features from the first column was familiar to every student. By the time the primary school students passed the test, they had studied these factors for several years already, as the comprehension and use of all the number characteristics given in the task are essential for further classes in mathematics. The pupils' teachers were asked these questions before the test: "Can your students distinguish five and four-digit numbers?", "Can they say whether a number is odd or even?" and "Do they know where the tens and hundreds positions are?" The teachers gave a positive answer to all the questions meaning that the students may have found this task type challenging not because of unfamiliar mathematical terms, but rather because of ignoring or forgetting all the conditions of the problem. A pupil who, for instance, chose option one, managed to prioritize only two features (oddness and 0 in hundreds unit) out of the required three. There might nonetheless be a way to explain the cause of such conduct. As the teacher talked through similar tasks in class, he guided his students by saying "What are the features the number that we are looking for has? Now search for these features in every number you see. Bear it in mind that the number you need must have all three features." Such guidance deprived the students of the possibility to manage their work as well as to demonstrate self-control by the analysis of the features of each number. Instead possible mistakes could be prevented provided the learning program incorporated solving such problems first with adult or peer assistance and eventually by children themselves so that they could independently determine a course of solving the problem and monitor whether all necessary steps have been taken and all requirements met.

As soon as in the course of this mathematical test the students were asked to solve two-step problems, another difficulty emerged. Some students failed to complete task by omitting the second step. Nowadays pupils face two-step problems starting from the first form and are supposed to accomplish them in the second and third forms. That is why any fourth grader may easily answer the question: "How many steps does it take to solve the problem? One or more?" The test intended for fourth graders included a two-step problem of this kind: " $1250 \mathrm{~kg}$ of apples were picked in the orchard. $80 \mathrm{~kg}$ turned out to be grubby and were left for horses. The rest were put into lug-boxes, $10 \mathrm{~kg}$ per box and sent to the shop. How many lug-boxes were sent to the shop?" $80 \%$ of the fourth graders managed to complete the task and got the right answer. The solutions suggested by the others (only $2 \%$ of the pupils did not even start the exercise, the same number of the students made a mistake in their calculations while performing the second step) show that the children accomplished the first step and immediately moved to writing down the answer to the whole task. Their solution looked the following way: " $1250-80=1170(\mathrm{~kg})$ ". Let us analyze it. The fourth grader was offered a familiar task, he understood that the solution to it consisted of more than one step; nonetheless, he accomplished it by performing only the first step. It could be induced by the fact that as pupils engage in an academic task, a lot of them pursue the attempt to obtain an answer (at least any answer) to it, whereas the course of solving the problem is perceived as unimportant and boring. As a result, these children lack experience in solving similar tasks, find it difficult to compare different methods and are unable to relate their answer to the right one. In this case, in order to enhance his students' performance the teacher could concentrate on fostering the skills of self-monitoring, as well as talking through the idea and the course of problem solving, and independent validation of the selected method (preceded by no additional instructions 
coming from the teacher) and the answer, regardless the difficulty of the task.

Group two. The student who constantly needs his teacher's assistance and encouragement may often substitute the appointed task with a different one. A simple illustration is found in the situation when the fourth grader substitutes a simple task (a one-step problem) with a more difficult one (a two-step problem).

Task 2. "Ivan Ivanovich caught 60 fish and put them in the bucket. Then a cat stole one tenth of all the fish from the bucket. Now there are ....
1) 60 fish fewer.
2) 50 fish fewer.
3) 6 fish fewer.

4) 54 fish fewer.»

The student needs to calculate the amount of the part (he is to determine one tenth of 60). Meanwhile approximately $20 \%$ of the pupils choose the wrong answer "54 fish fewer". Thus they answer the question "How many fish are left in the bucket?" upon solving this task: "Ivan Ivanovich caught 60 fish and put them in the bucket. Then a cat stole one tenth of all the fish from the bucket. How many fish are left in the bucket?" The task around the question "How much/ many ... is/are left?" is more complicated than the initial one and consists of two steps. However, as in their primary school years pupils usually address this kind of problems more often than the tasks with determining the amount of the part; they tend to substitute a simple problem with a more complex one.

The lack of learner autonomy may also be reflected in self-management during the test. Children know that they may skip difficult problems. Nonetheless, a lot of pupils skip them not because they have carefully read the task, assessed their ability, and decided it would be 'difficult to accomplish', 'impossible to complete' or they would 'most likely make mistakes', 'never predict the outcome', 'come back to it at the end of the test', and 'solve it at the end of the lesson', if they had time. The reason is that they know they 'may skip some problems'. The facts that these students have not mastered the learning operations of self-control yet ("Have I completed all the tasks?", "Does the answer correspond to the question?") and lack persistence ("I am to do all the tasks.") are the main reasons for the children's reluctance to go back to the problems they have skipped, their second refusal to accomplish them and their attempt to hand in half-finished papers as soon as possible.

Group 3. The absence of initiative or interest in one's work and instructions emerge as students perform tasks that require the application of knowledge from different topics and units. Unless students are self-directed, they are unlikely to take up more challenging tasks, reluctant to go back to the text, instead they make use of calculators, refuse to determine other ways to solve the problem and so on. All the tasks that are to be related to complementary information, life and academic experience seem overwhelming to them.

A simple illustration is a way such students perform tasks with geometric variables. One of the most common mistakes is the confusion of the terms 'perimeter' and 'area'. How can it be related to the lack of learner autonomy? It is generally accepted that most primary school students are capable determining perimeter or area easily. Nevertheless, in order to understand how to do it in this or that situation, the student has to demonstrate autonomy and ask himself: "What am I looking for? How should it look like? What rules/formulae do I need?", "Will I determine the perimeter this way?", "What is it that I am trying to determine, the perimeter or the area?" and so on. Possible mistakes can be prevented by work in pairs or groups. In this case, the children explain it to each other what and how they are going to do and comment on their problem solving. If one student measures the area and gives the answer in linear units $(\mathrm{cm}, \mathrm{m})$ instead of square units $\left(\mathrm{cm}^{2}, \mathrm{~m}^{2}\right)$, the other student might notice it as the teacher usually monitors whether the right units are employed for measurements.

Let us now define the strategies that enhance selfdirected learning, improve the student's performance and increase his interest in learning.

\section{How to develop learner's autonomy}

The first strategy is to include individual work and searching out of information into the curriculum. Selfdirected learning is "the child's ability to accomplish tasks without adult assistance and at the same time to request it where necessary, as well as his ability to evaluate independently the assistance received from such sources as an authoritative adult, textbook and so on" [4]. Individual tasks, which are aimed at providing the student with the opportunity to complete them on his own or request assistance if necessary, should be integrated in any lesson plan. As the student is encouraged to perform a task individually, he learns to assess his self-efficacy and ability to understand the tasks, complete it, validate the answer and correct his mistakes in the solution and the outcome. The encouragement of self-directed learning motivates students to "discover" new learning methods and seek new solutions, explanations and arguments.

The main stages of search or study are to formulate the problem, to put forward a hypothesis and to test it [5]. If the student is regularly involved in such activities, he learns to set a learning goal, stay focused on it, request assistance, accept the responsibility for his paper's quality and defend his opinion ("my hypothesis was right", "my hypothesis turned out to be wrong, but I learnt that..").

The second strategy is to develop special learning skills that characterize learner autonomy, in particular the sills of self-assessment and self-control. These skills can be defined through the main learning operations, which constitute the skills and are mastered by the child at early learning stages.

Self-assessment:

- task selection in compliance with one's ability,

-ability to foresee and analyze the course of problem solving,

- conscious request for assistance,

- ability to draw a conclusion on one's competence and incompetence.

Self-control: 
- realization of the necessity to monitor the steps of the task accomplishment (the student is ready to answer the question "what am I doing right now?"),

- application of learning skills to task solving,

- validation of the outcome (the answer),

- ability to identify a mistake,

- readiness to explain possible causes of mistakes,

- desire to correct mistakes,

- analysis of solutions and methods ("is it correct?", "is it reasonable?").

The third strategy is to combine different types of work (individual, in pairs, and in groups) during the lesson. Whereas the student may be unwilling or lack knowledge to accomplish a task without assistance, any task is typically first completed with peer assistance and then eventually by the child himself. There are special exercises in modern primary school textbooks such as "Let's Discuss", "Work in Pairs", "Work with your Peer" and "Individual Task". The teacher may use such tasks to turn episodic occurrences of learner autonomy into regular ones. The incorporation of different forms of the learning process organization enhances the student's chances to accomplish more challenging tasks and encourages them to resolve non-typical learning situations (to seek a new solution or several solutions, to use patterns).

\section{Conclusion}

Regular and systematic development of learning competence and learner autonomy is one of the basic requirements of the Federal State Educational Standard. Furthermore, in order to develop self-directed students, the teacher should avoid setting limitations, offer opportunities for individual searching out of information and give no negative feedback on the mistakes made in the process of learning.

\section{References}

1. Federal'nyi gosudarstvennyi obrazovatel'nyi standart nachal'nogo obshchego obrazovaniya (Prosveshchenie, Moscow, 2011) [In Rus]

2. G.S. Kovaleva, K.A. Krasnyanskaya, and O.A. Rydze, Matematika: standartizirovannye materialy dlya itogovoi attestatsii: 4 klass (Prosveshchenie, Moscow, St. Petersburg, 2013) [In Rus]

3.O.A. Rydze, Sposoby ucheta otdel'nykh rezul'tatov itogovykh rabot po matematike mladshikh shkol'nikov. (ID Delo, Moscow, 2014) [In Rus]

4. G.A. Tsukerman, and A.L. Venger, Razvitie uchebnoi samostoyatel'nosti. (Otkrytyi institut "Razvivayushchee obrazovanie", Moscow, 2010) [In Rus]

5.N.F. Vinogradova, Nachal'noe obrazovanie, 4, 3-6

(2014) [In Rus] 